\title{
Aptitude and attitude: predictors of performance during and after basic laparoscopic skills training
}

\author{
Kirsty L. Beattie ${ }^{1}$ (1) - Andrew Hill ${ }^{1,2,3} \cdot$ Mark S. Horswill $^{1}$ Philip M. Grove ${ }^{1} \cdot$ Andrew R. L. Stevenson $^{4,5}$
}

Received: 23 February 2021 / Accepted: 24 July 2021 / Published online: 9 August 2021

(C) The Author(s) 2021

\begin{abstract}
Background Manual dexterity and visual-spatial ability are considered key to the development of superior laparoscopic skills. Nevertheless, these abilities do not reliably explain all the variance found in the technical performance of surgical trainees. Consequently, we must look beyond these abilities to improve our understanding of laparoscopic skills and to better identify/develop surgical potential earlier on.

Purpose To assess the individual and collective impact of physical, cognitive, visual, and psychological variables on performance during and after basic simulation-based laparoscopic skills training.

Method Thirty-four medical students (laparoscopic novices) completed a proficiency-based laparoscopic skills training program (using either a 2D or 3D viewing mode). This was followed by one testing session, a follow-up testing session with new (yet similar) tasks, and a series of physical, cognitive, visual, and psychological measures.

Results The statistical models that best predicted variance in training performance metrics included four variables: viewing mode (2D vs $3 D)$, psychological flexibility, perceived task demands, and manual dexterity (bimanual). In subsequent testing, a model that included viewing mode and manual dexterity (assembly) best predicted performance on the pre-practiced tasks. However, for a highly novel, spatially complex laparoscopic task, performance was best predicted by a model that comprised viewing mode, visual-spatial ability, and perceived task demands. At follow-up, manual dexterity (assembly) alone was the best predictor of performance on new (yet similar) tasks.

Conclusion By focussing exclusively on physical/cognitive abilities, we may overlook other important predictors of surgical performance (e.g. psychological variables). The present findings suggest that laparoscopic performance may be more accurately explained through the combined effects of physical, cognitive, visual, and psychological variables. Further, the results suggest that the predictors may change with both task demands and the development of the trainee. This study highlights the key role of psychological skills in overcoming initial training challenges, with far-reaching implications for practice.
\end{abstract}

Keywords Laparoscopy $\cdot$ Skill $\cdot$ Ability $\cdot$ Potential $\cdot$ Training $\cdot$ Psychology

Kirsty L. Beattie

kirsty.beattie@uq.net.au

1 School of Psychology, The University of Queensland, Brisbane, Australia

2 Clinical Skills Development Service, Metro North Hospital and Health Service, Brisbane, Australia

3 Minerals Industry Safety and Health Centre, Sustainable Minerals Institute, The University of Queensland, Brisbane, Australia

4 School of Medicine, The University of Queensland, Brisbane, Australia

5 Department of Colon and Rectal Surgery, Royal Brisbane and Women's Hospital, Brisbane, Australia

\section{Background}

With an exponential growth in minimally invasive procedures and a shift towards shorter workweeks in many countries, surgical residents now face a greater complexity of practice with potentially fewer opportunities for operational experience [1,2]. While robotic approaches may help to overcome the various learning difficulties associated with minimally invasive surgery, the development of laparoscopic skills remains fundamental to achieving safe and efficient outcomes. Nevertheless, trainees have been found to acquire laparoscopic skills at different rates, with $8-20 \%$ failing to reach proficiency in simulation-based laparoscopic skills training, regardless of continued practice [3-5]. As a result, 
it is essential that the chosen few possess the necessary knowledge, skills, abilities, and attributes to reach laparoscopic proficiency with greater efficiency and efficacy. However, the most important predictors of surgical potential are still a point of conjecture and debate. While research shows that academic achievements (e.g. grades, test knowledge) are limited in their ability to predict surgical performance [6-8], many surgeons believe that certain innate abilities are the key to superior laparoscopic skill [7].

\section{Innate abilities}

When 58 master surgeons were asked to identify the most important attributes for surgical trainees, innate dexterity was reported as the strongest perceived predictor of technical skill in both training and practice [7]. This incorporated psychomotor abilities such as hand-eye coordination, limb coordination, speed, and steadiness (i.e. manual dexterity), as well as spatial perception, and the ability to visually interpret and manipulate images (i.e. visual-spatial ability) [7]. Moreover, these abilities were considered particularly vital for the development of laparoscopic skills to manage the visuomotor discordance and increased technical complexity created by the fulcrum effect (i.e. the counterintuitive movements required by the perceived inversion of motion from the handle to the end of the instrument) [7, 9].

Empirical research has since shown significant correlations of both manual dexterity and visual-spatial ability with novices' technical performance (i.e. efficiency and accuracy) in laparoscopic skills training [10-15]. While these relationships have not always been observed [16, 17], inconsistent and conflicting results may be due to various methodological limitations common in this research field. For example, many studies have neglected to assess or control for potentially confounding visual variables (e.g. visual acuity, stereoacuity) that may impact laparoscopic performance, particularly with different viewing modes (i.e. 2D and 3D) $[18,19]$. Furthermore, past research has often focussed on the independent effects of manual dexterity [17], visual-spatial ability [20], and visual ability [21], yet their combined effects have been found to explain a greater portion of variance in laparoscopic performance [22, 23]. While design differences may account for some of the inconsistent findings throughout the literature, variance still exists in the performance of surgical trainees that cannot be explained by the individual or combined effects of such innate abilities [22]. Consequently, it is important to expand beyond the scope of past research and consider other individual differences that may account for further variance in performance and enhance the prediction of surgical potential.

\section{Perceived demands}

Research has shown that higher levels of stress (i.e. where internal/external demands are perceived by the individual as a threat rather than a challenge) are associated with poorer surgical performance (i.e. longer times and increased errors), and inferior economy of motion during laparoscopic skills training and practice [24-26]. Excessive levels of stress have also been found to disrupt and relocate limited attentional resources and impair visual-spatial ability, hand-eye coordination, memory, situation awareness, and decision-making in various high-stakes contexts [27-29]. Such results suggest that a surgeon's innate physical and cognitive abilities may be significantly impacted by their psychological state and the way they perceive internal and external demands [25]. For example, if a surgeon becomes overwhelmed at critical points of complexity and pressure, their normally quick hand movements and cognitive processing may be interrupted or impaired.

To address these concerns, many researchers have attempted to predict how candidates will work under pressure by defining the ideal psychological states, traits, characteristics, behaviours, and/or coping strategies of practicing surgeons [30-38]. However, the results have ultimately lacked clarity, consistency, and an objective and reliable connection with technical skill $[39,40]$. It is suggested that such limitations are likely due to the ill-defined labels used to identify levels of expertise (e.g. the skills and abilities of a "master surgeon" have yet to be defined), and the inaccurate assumptions that years of surgical experience reflect a particular level of surgical skill [41]. More importantly, this area of research has largely overlooked why individuals subjectively evaluate the same demand in different ways (e.g. why one individual sees it as a challenge, while another sees it as a threat), and how this impacts subsequent performance [42]. As a result, we must look beyond the surgical literature to better understand the key psychological mechanisms behind perception and performance in this high-stress and high-demand contexts.

\section{Psychological flexibility}

In other high-stakes fields such as aviation, the military, and elite sports, an attribute known as psychological flexibility has been consistently found to impact well-being, stress, technical and non-technical performances, and skill development under pressure [43-48]. For example, greater psychological flexibility has been associated with increased resilience and reduced risk of posttraumatic stress in active Air Force personnel, improved decision-making in aircrew, and higher coach-ratings of athlete' performances [43-48]. 
Psychological flexibility can be described as the ability to remain aware and engaged in one's present experience without internal distraction, while persisting or changing actions towards chosen goals or values [46, 49]. It is important to note that psychological flexibility is not simply a state of happiness, well-being, positivity, or ease, but rather involves functional responses to difficult, uncertain, and challenging thoughts/feelings/situations [50]. Furthermore, improving psychological flexibility is the core function of mindfulnessbased practice (a growing area involving stress-reduction techniques) [51-53], which is considered to benefit performance by reducing the attentional resources spent trying to change, control, judge, or avoid internal thoughts or events [54]. This then leaves greater awareness available for task-relevant cues and more effective responding to contingencies in the environment [54]. As surgical excellence is not marked by error-free performance, but rather the ability to manage errors, disruptions, and complications, and efficiently change techniques and strategies to meet these challenges [55, 56], it is suggested that a surgeon's psychological flexibility may carry significant implications in the operating theatre.

While it appears that psychological flexibility has yet to be explored in a surgical context, it has been associated with increased emotion regulation, self-efficacy, resilience, and work performance in other health professions [57-59]. Additionally, Lebares et al. (2019) [60] found that surgical residents who completed laparoscopic skills training in combination with a mindfulness-based training intervention, showed improved well-being, executive functioning, and motor performance at a 1-year follow-up, compared to residents who completed laparoscopic skills training alone. This suggests that more mindful and flexible behaviours may enhance surgical performance by optimising attentional resources and reducing the deleterious effects of stress. This may also help to explain why certain individuals perceive and react to demands in different ways, and how this changes their performance. However, this point remains conjecture given the lack of investigation into psychological flexibility within a surgical context. Also, to the authors' knowledge, no published empirical study has explored psychological variables in combination with physical, cognitive, and visual abilities to examine their individual and collective impact on laparoscopic skills.

\section{Aims}

To expand beyond past research, the study had two main aims. The first aim was to assess the individual and collective impact of (a) manual dexterity, (b) visual-spatial ability, and (c) visual abilities (i.e. visual acuity and stereoacuity) on performance in proficiency-based laparoscopic skills training and testing (while controlling for viewing mode: 2D/3D). The second aim was to assess the individual and collective impact of (d) perceived demands and (e) psychological flexibility on performance in proficiency-based laparoscopic skills training and testing (beyond that of other variables). By enhancing our ability to predict surgical potential, it may be possible to equip medical students to make more informed decisions about their suitability for a surgical career early on, and allow them to focus on developing all relevant supportive skills/attributes prior to formal selection and training. Moreover, by the time they reach surgical residency, applicants may be more likely to possess the necessary aptitude and attitude to reach laparoscopic proficiency with increased efficiency and efficacy.

\section{Method}

\section{Participants}

Thirty-four laparoscopic novices (male, $n=18$; female, $n=16)$ with a mean age of 25.29 years $(S D=3.66$, range 19-34) voluntarily participated in this study. Participants were current medical students (between the first and fourth year of medical school), recruited from a larger sample who participated in Beattie et al.'s (2020) [61] study investigating the effects of $2 \mathrm{D}$ vs $3 \mathrm{D}$ viewing modes on laparoscopic skills training. Thirty-two participants were right-handed and two were left-handed. Participants received no financial compensation for their involvement. The study was approved by the Royal Brisbane and Women's Hospital (RBWH) and the University of Queensland ethical committees.

\section{Materials and measures}

\section{Laparoscopic tasks}

Training tasks Participants performed all six tasks from the 3-Dmed program (3-Dmed $®$, Franklin, OH, US) to a baseline level of proficiency (see Table 1) using a box trainer and laparoscopic instruments. Total scores were calculated by the total time taken (in seconds), combined with the total time penalties incurred for errors across all training repetitions (in seconds). Consequently, lower scores reflected more efficient and accurate performances. All baseline levels of proficiency, error parameters, and instructions outlined by Schreuder et al. (2011) [62] were adopted in this research (see Table 1 for an overview of the six tasks).

Testing tasks During testing, participants completed all 3-Dmed tasks again (twice) with the same scoring parameters, followed by a novel task developed and validated by Sakata et al. (2017) [18, 63], known as the "Navigating in Space" task (NIS). The NIS task assesses fine dexterity and 
Table 1 Overview of the 3-Dmed tasks used in training and testing (parameters adopted from Schreuder et al. 2011)

\begin{tabular}{|c|c|c|c|}
\hline Task & $\begin{array}{l}\text { Proficiency } \\
\text { Score (in } \\
\text { seconds) }\end{array}$ & Penalties & Description \\
\hline 1. Post and sleeve & 120 & $\begin{array}{l}\text { Drop sleeve } \text { on the board }=10 \mathrm{~s} \\
\text { Drop sleeve off the board }=20 \mathrm{~s}\end{array}$ & $\begin{array}{l}\text { Pick up and transfer six sleeves from one side of the board to the } \\
\text { other, and back again, using both hands }\end{array}$ \\
\hline 2. Loops and wire & 86 & Miss a loop $=10 \mathrm{~s}$ & $\begin{array}{l}\text { Feed two pipe cleaners through two rows of loops using both } \\
\text { hands, starting one from the left side and one from the right } \\
\text { side }\end{array}$ \\
\hline 3. Pea on a peg & 313 & $\begin{array}{l}\text { Drop bead on the board }=10 \mathrm{~s} \\
\text { Drop bead off the board }=20 \mathrm{~s}\end{array}$ & $\begin{array}{l}\text { Pick up wooden beads from a cup and place them onto } 14 \text { pegs, } \\
\text { using the right hand to complete the right side and the left hand } \\
\text { to complete the left side }\end{array}$ \\
\hline 4. Wire chaser (one hand) & 69 & Lose/drop the ring $=10 \mathrm{~s}$ & $\begin{array}{l}\text { Move three rings of decreasing diameter to the other end of a } \\
\text { curved wire with one hand }\end{array}$ \\
\hline 5. Wire chaser (two hands) & 127 & Lose/drop the ring $=10 \mathrm{~s}$ & $\begin{array}{l}\text { Move three rings of decreasing diameter to the other end of a } \\
\text { curved wire with two hands }\end{array}$ \\
\hline 6. Zig-zag loop & 48 & Miss a loop $=10 \mathrm{~s}$ & $\begin{array}{l}\text { Alternately feed a rope through the first and second rows of } \\
\text { loops using both hands to make an "M"-shaped or zigzag pat- } \\
\text { tern }\end{array}$ \\
\hline
\end{tabular}

required participants to pass a curved suture through six flexible loops (made from a monofilament strand) in a predefined sequence with two needle holders. Scores on the NIS task were calculated by the total time taken (in seconds) to complete the last two repetitions of the task (with a time limit of 10 min per attempt). The first attempt was used to familiarise participants with the task requirements.

Follow-up tasks In the follow-up session, participants completed the first two tasks from the FLS training program (i.e. Peg Transfer and Precision Cutting) three times each. Similar to the first 3-Dmed task (i.e. Post and Sleeve), the Peg Transfer task required participants to pick up and transfer six objects from one side of the board to the other, and back again, using both hands. The Precision Cutting task required participants to use a grasper in one hand to provide traction to a piece of gauze, and endoscopic scissors in the other hand to cut around a pre-marked double-circle on the gauze. All standard instructions and scoring parameters defined by the FLS program (https://www.flsprogram.org/) were adopted here.

\section{Innate abilities}

With manual dexterity, visual-spatial ability, visual acuity, and stereoacuity found to significantly correlate with laparoscopic training performance [13-15, 18], participants were assessed on these variables as baseline measures of physical, cognitive, and visual ability in the screening session. The Purdue Pegboard (PP) test (Lafayette Instrument Co) was used to measure innate manual dexterity through four subtests: right hand (alone), left hand (alone), bimanual (both hands together), and an assembly task (both hands working simultaneously and continuously to construct assemblies with multiple elements). Higher scores on the PP reflected superior manual dexterity. An online version of the Mental Rotations Test was used to assess participants' visualspatial ability, with higher scores reflecting more efficient and accurate visual-spatial ability [64]. Participants' right and left visual acuity, and their level of stereoacuity were also assessed using the LogMAR eye chart (National Vision Research Institute, Melbourne, Australia) and Randot Stereo Test (Stereo Optical, Chicago, IL), respectively. In both these tests, lower scores reflected a greater level of visual ability.

\section{Perceived demands}

With high levels of stress found to negatively impact laparoscopic performance [65], participants completed the wellvalidated NASA Task Load Index (NASA-TLX) [66, 67] at the end of each session to assess the level of mental demand, physical demand, temporal demand, performance, effort, and frustration/stress that they associated with the tasks. Participants rated each of these dimensions on a 7-point scale [68] from Very Low (scored 0\%) to Very High (scored 100\%), except for performance, which was anchored at Perfect (scored 0\%) and Failure (scored 100\%). Lower scores on the index indicated less demand/stress perceived from the tasks.

\section{Psychological flexibility}

Participants' level of psychological flexibility was measured using the validated 7-item Acceptance and Action Questionnaire-II (AAQ-II; [69]). An example statement from the AAQ-II includes "Worries get in the way of my success". Each statement required a response on a 7-point scale from 1 
(never true) to 7 (always true). All responses were reversed scored so that higher scores reflected a higher level of psychological flexibility, and lower scores reflected greater experiential avoidance (or inflexibility).

Despite being recruited through a surgical interest group (requiring self-selection), participants' "interest in surgery compared to the average medical student" was also measured on a 5-point scale from Very Low (1) to Very High (5), to confirm if the sample adequately represented those interested in a surgical career. While other exploratory variables were also included as part of a larger body of research (e.g. level of medical study, video-game use; see Beattie et al. 2020 [61]), they were not the focus of the current study (and did not display any significant relationships with performance), thus are not discussed here.

\section{Procedure}

Participants attended five sessions at a simulation training centre within a tertiary hospital campus, and the first four sessions overlapped with the study conducted by Beattie et al. (2020) [61]. See Fig. 1 for an overview of the complete study design. The first session included the collection of background information and baseline measures of physical, cognitive, and visual abilities. The second and third sessions included the set practice of six laparoscopic skills tasks to a pre-defined level of proficiency using either a $2 \mathrm{D}$ or $3 \mathrm{D}$ viewing mode. The $3 \mathrm{D}$ viewing mode was included to control for its effects on performance (given 3D has the potential for more common use in future due to its efficacy in training) $[18,61]$. The fourth session included testing of the six tasks again (twice) and three attempts at a novel task. See Beattie et al. (2020) [61] for further details of the methodology and materials involved.

After completing the fourth session, all participants were invited to participate in a fifth (follow-up) session that was unique to the current study. During this fifth session, participants completed the first two tasks from the Fundamentals of Laparoscopic Skills (FLS) training program (to which they had no prior exposure) three times each in the $2 \mathrm{D}$ viewing mode. These tasks were followed by a series of psychological and behavioural measures administered online via the Qualtrics survey platform. It is noted that 23 (out of the 34) participants completed the psychological and behavioural measures via Qualtrics using a laptop in the simulation centre. However, due to COVID-19 restrictions on face-to-face research at the time of the study, 11 participants completed the same psychological and behavioural measures via Qualtrics outside of the simulation centre and could not undertake the two FLS tasks in the follow-up session.

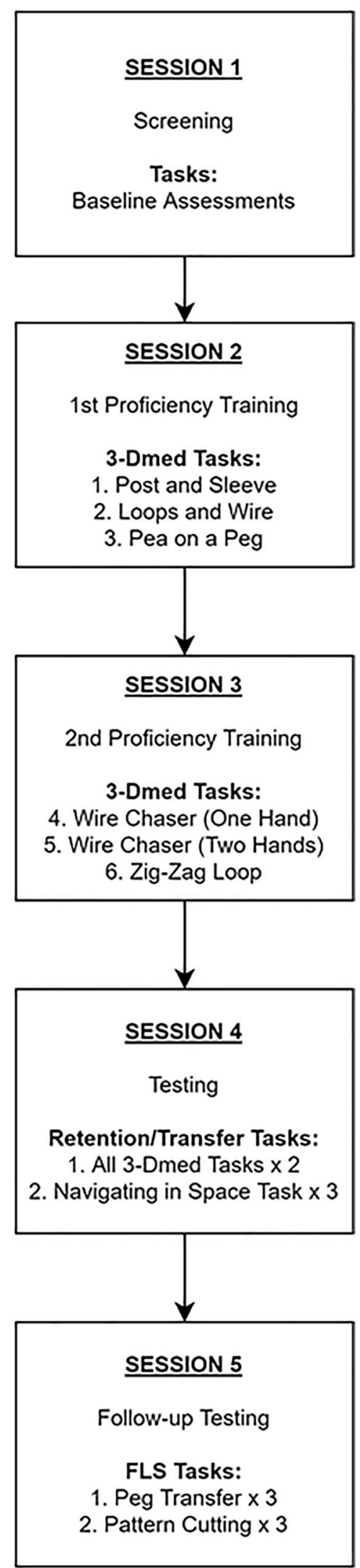

Fig. 1 Overview of study design 


\section{Statistical analysis}

Statistical analyses were conducted using SPSS $®$ version 25 (IBM Corp, 2017, Armonk, NY: USA), with $\alpha$ set at 0.05. Independent $t$-tests were run to check for any significant differences between participants who completed the online psychological/behavioural measures in the lab versus outside the lab. To identify the variables for inclusion in multivariate analyses, bivariate correlations among all potential predictor and criterion variables were assessed using Pearson's correlation coefficients (see Table 2). Any predictor variable that did not have a significant relationship $(p>0.05)$ with any of the criterion variables was excluded from further analyses. After satisfying the mathematical assumptions for multivariate analyses [70], a series of combined hierarchical stepwise regressions was conducted to predict the individual and collective impact of the associated variables on each criterion, respectively (i.e. training repetitions, total training score, total test score, total NIS score, and total follow-up test score). To control for its already well-established effects on laparoscopic performance $[61,71,72]$, the viewing mode variable (coded as $2 \mathrm{D}=0$ and $3 \mathrm{D}=1$ ) was entered into Step One of each analysis (except for follow-up testing where participants used 2D only) using the Enter method. Given the exploratory nature of this study, and to avoid overfitting the model, all significantly associated predictor variables were then entered into Step Two using the Stepwise method (to determine the line of best fit with inclusion criteria set at $p<0.05$, exclusion at $p>0.10$, and order based on explanatory power) [70]. Despite the relatively small $N$ for the number of predictors employed, the sample size per variable still met the minimum requirements suggested in the literature [73, 74]. Additionally, the adjusted $R^{2}$ is reported here (in addition to the conventional $R^{2}$ in Tables 3 - 7) to further account for the relatively small sample size (as suggested by Austin and Steyerberg, 2015 [73]).

\section{Results}

\section{Participants}

Overall, participants reported a High mean interest in surgery (compared to the average medical student) $(M=4.00$, $S D=0.82$ ). Participants' mean scores across all other variables of interest are shown in Table 2. There were no significant differences in the characteristics, survey responses, or performances during training or testing between participants who completed the follow-up measures online in the lab vs outside the lab (all $p$ 's $>0.05$ ). Furthermore, there were no changes in any of the relationships between variables (in significance or direction) after the additional responses/ performances were included from these participants.

\section{Training}

\section{Repetitions}

Bivariate correlations showed significant relationships between total training repetitions and viewing mode (in training), psychological flexibility, perceived demands (in training), and manual dexterity (bimanual) (see Table 2). Equally, the final model to predict total training repetitions included training viewing mode (control variable), perceived demands (training), psychological flexibility, and manual dexterity (bimanual). All associated analyses are shown in Table 3 . The final model was statistically significant, $F(4$, $29)=15.33, p<0.001$, and explained $63.5 \%$ of the variance in total training repetitions, $R_{\text {Adj }}^{2}=0.635$ (large effect). When controlling for the effects of other predictors, the results showed that as psychological flexibility increased, the number of training repetitions required to reach proficiency significantly decreased (i.e. performance improved). Additionally, as perceived demands increased, the number of training repetitions significantly increased (i.e. performance worsened), and as manual dexterity (bimanual) improved, training repetitions significantly decreased. Overall, after controlling for viewing mode, psychological flexibility uniquely accounted for $19.5 \%$ of the variance in total training repetitions, while perceived demands accounted for $13.1 \%$, and manual dexterity (bimanual) accounted for $6.4 \%$.

\section{Total Training Score}

Bivariate correlations showed significant relationships between total training score and viewing mode (in training), perceived demands (in training), psychological flexibility, and manual dexterity (bimanual) (see Table 2). Equally, the final model to predict total training score included training viewing mode (control variable), perceived demands (training), psychological flexibility, and manual dexterity (bimanual). All associated analyses are shown in Table 4. The final model was statistically significant, $F(4,29)=17.12$, $p<0.001$, and explained $66.2 \%$ of the variance in total training score, $R_{\text {Adj }}^{2}=0.662$ (large effect). When controlling for the effects of other predictors, the results showed that as psychological flexibility increased, the total training score (time + errors) significantly decreased (i.e. performance improved). Additionally, as perceived demands increased, the total training score significantly increased (i.e. performance worsened), and as manual dexterity (bimanual) improved, total training score significantly decreased. Overall, psychological flexibility uniquely accounted for $20 \%$ of the variance in total training score, perceived demands accounted for $15 \%$, and manual dexterity (bimanual) accounted for $7.4 \%$. 


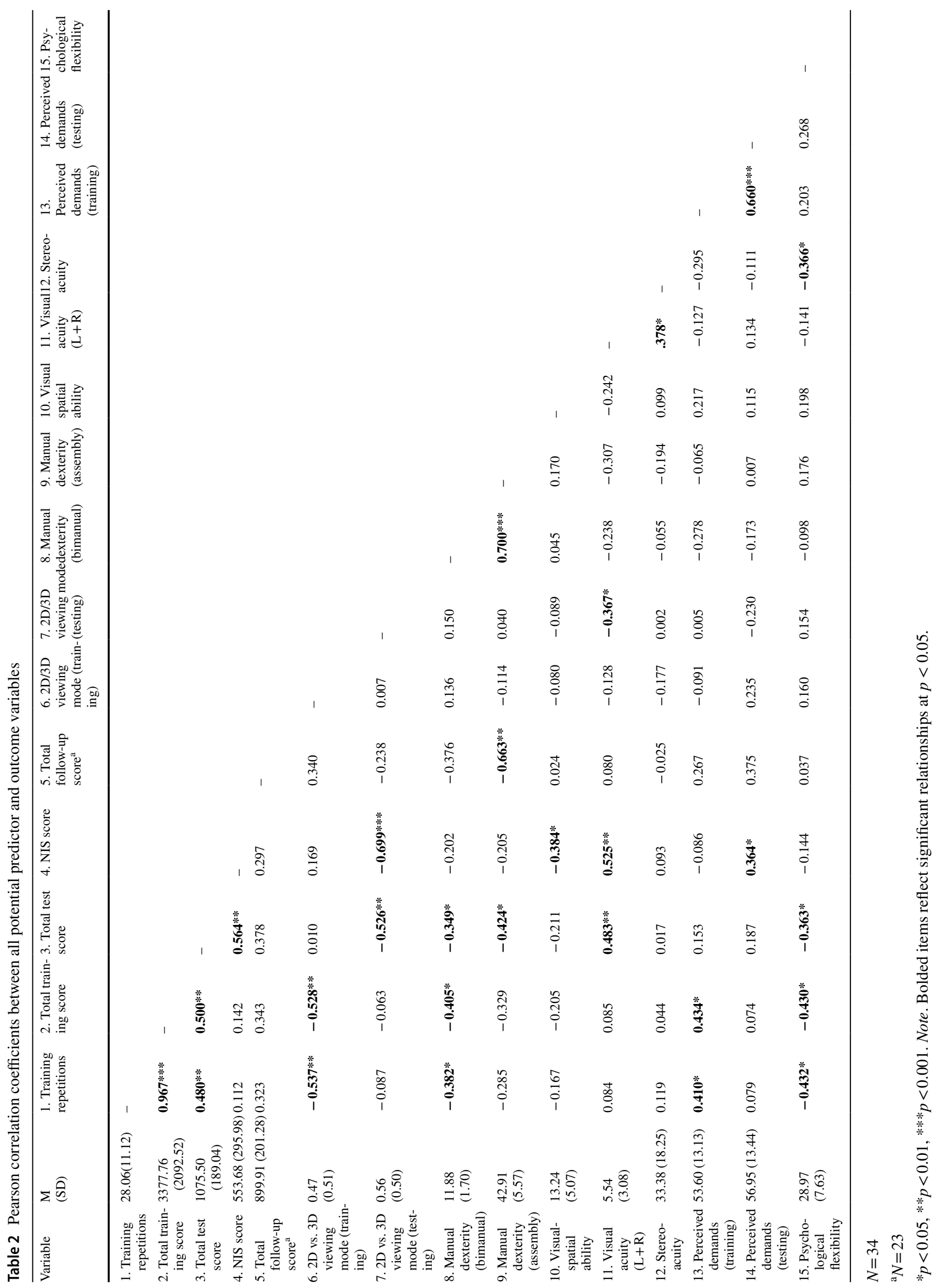




\section{Testing}

Bivariate correlations showed significant relationships between total test score and viewing mode (in testing), visual acuity, manual dexterity (bimanual), manual dexterity (assembly), and psychological flexibility (see Table 2). Despite this, the final model to predict total test score included test viewing mode (control variable) and manual dexterity (assembly) only. All associated analyses are shown in Table 5. The final model was statistically significant, $F(2$, $31)=12.15, p<0.001$, and explained $40.3 \%$ of the variance in total test score, $R_{\text {Adj }}^{2}=0.403$ (medium-to-large effect). When controlling for the effects of test viewing mode, the results showed that as manual dexterity (assembly) increased, the total test score (time + errors) significantly decreased (i.e. performance improved), with manual dexterity (assembly) uniquely accounting for $16.3 \%$ of the variance in test performance.

\section{Novel task (NIS)}

Bivariate correlations showed significant relationships between total NIS score and viewing mode (in testing), visual acuity, visual-spatial ability, and perceived demands (in testing) (see Table 2). However, the final model to predict total NIS score included test viewing mode (control variable), visual-spatial ability, and perceived demands (testing). All associated analyses are shown in Table 6. The final model was statistically significant, $F(3,30)=30.68$, $p<0.001$, and explained $73.0 \%$ of the variance in total NIS score, $R_{\text {Adj }}^{2}=0.730$ (large effect). When controlling for the effects of test viewing mode, the results showed that as visual-spatial ability increased, the total NIS score (completion time) significantly decreased (i.e. performance improved). Additionally, as perceived demands increased, the total NIS score increased (i.e. performance worsened). Overall, visualspatial ability uniquely accounted for $20.1 \%$ of the variance in NIS task performance, while perceived demands accounted for $6.4 \%$.

\section{Follow-up tasks}

Bivariate correlations showed a significant relationship between follow-up score and manual dexterity (assembly) (see Table 2). Consequently, the final model to predict total follow-up score included manual dexterity (assembly) alone. Associated analyses are shown in Table 7. The final model was statistically significant, $F(1,21)=16.50, p=0.001$, with manual dexterity (assembly) uniquely explaining $41.3 \%$ of the variance in total follow-up score, $R_{\mathrm{Adj}}^{2}=0.413$ (mediumto-large effect). The results showed that as manual dexterity (assembly) improved, the total follow-up score (time + errors) significantly decreased (i.e. performance improved).

\section{Discussion}

The aim of this study was to expand on past research and assess the impact of physical, cognitive, visual, and psychological variables on novices' performance in basic laparoscopic skills training and testing. Results indicated that (a) manual dexterity, (b) visual-spatial ability, (c) visual abilities (i.e. visual acuity), (d) perceived demands, and (e) psychological flexibility were all independently correlated with at least one aspect of performance during proficiency-based laparoscopic skills training and/or subsequent testing. However, when collectively assessing the variables and controlling for the well-known effects of viewing mode (i.e. $2 \mathrm{D}$ vs 3D) on performance, the results suggest that certain psychological functions (i.e. psychological flexibility and perceived demands) were key to efficiently overcoming the initial challenges involved in training to proficiency. Then, once these challenges were met (i.e. proficiency was achieved and participants were performing at a relatively equivalent level), innate abilities appeared to take centre stage and exert a greater influence on subsequent performance. Despite this, the value of each individual ability did not remain equivalent across each task and stage of practice. For example, we found that basic two-handed dexterity was more predictive of performance during training (when participants were still becoming familiar with the basic movements and tasks), while the two-handed assembly task (requiring more complex, simultaneous, and continuous movements with multiple elements) was more predictive of performance in later testing of pre-practiced and new (more complex) FLS tasks. It must be noted that, to the authors' knowledge, the various aspects of manual dexterity have never been broken down in previous studies to explore how they respectively impact performance during the different stages of laparoscopic skills training. This may help to explain why inconsistent outcomes have been identified in past research, as manual dexterity has been conceptualised and measured in different ways (e.g. performance on a laparoscopic task, or a total score on a grooved pegboard test $[16,17])$.

Furthermore, while visual-spatial ability did not account for a significant portion of variance in participants' training performance (beyond that of physical ability and psychological perception), it explained a significant portion of variance in performance when the task increased in spatial complexity (i.e. in the NIS task). Similarly, while perceived task demands (in testing) did not account for any significant difference in the final model predicting participants' test performance (of pre-practiced tasks), these perceptions did predict a significant portion of variance in performance when 
Table 3 Summary of combined hierarchical stepwise regression analyses for variables predicting total training repetitions

\begin{tabular}{|c|c|c|c|c|c|c|c|c|c|}
\hline \multirow{2}{*}{$\begin{array}{l}\text { Total training repetitions } \\
\text { Variable }\end{array}$} & \multicolumn{3}{|c|}{ Model 1 (Control) } & \multicolumn{3}{|c|}{ Model 2 (Final) } & \multirow[t]{2}{*}{$R^{2}$} & \multirow[t]{2}{*}{$R_{\mathrm{adj}}^{2}$} & \multirow[t]{2}{*}{$R^{2}$ change } \\
\hline & $B$ & SE & $\beta$ & $B$ & SE & $\beta$ & & & \\
\hline Constant & 33.61 & 2.25 & - & 54.77 & 11.75 & - & & & \\
\hline $2 \mathrm{D}$ vs. $3 \mathrm{D}$ viewing mode (training) & -11.80 & 3.27 & $-0.54 * *$ & -8.53 & 2.38 & $-0.39 * *$ & 0.289 & 0.267 & $0.289 * *$ \\
\hline Perceived demands (training) & & & & 0.34 & 0.10 & $0.40 * *$ & 0.420 & 0.383 & 0.131* \\
\hline Psychological flexibility & & & & -0.69 & 0.16 & $-0.48 * * *$ & 0.615 & 0.577 & $0.195 * *$ \\
\hline Manual dexterity (bimanual) & & & & -1.74 & 0.72 & $-0.27 *$ & 0.679 & 0.635 & $0.064 *$ \\
\hline
\end{tabular}

$N=34$

${ }^{*} p<0.05, * * p<0.01, * * * p<0.001$. Note. Bolded items reflect significant relationships at $p<0.05$.

Table 4 Summary of combined hierarchical stepwise regression analyses for variables predicting total training score

\begin{tabular}{|c|c|c|c|c|c|c|c|c|c|}
\hline \multirow{2}{*}{$\begin{array}{l}\text { Total training score } \\
\text { Variable }\end{array}$} & \multicolumn{3}{|c|}{ Model 1 (control) } & \multicolumn{3}{|c|}{ Model 2 (final) } & \multirow[t]{2}{*}{$R^{2}$} & \multirow[t]{2}{*}{$R_{\text {adj }}^{2}$} & \multirow[t]{2}{*}{$R^{2}$ change } \\
\hline & $B$ & SE & $\beta$ & $B$ & SE & $\beta$ & & & \\
\hline Constant & 4404.78 & 425.23 & - & 8529.96 & 2127.83 & - & & & \\
\hline $2 \mathrm{D}$ vs. $3 \mathrm{D}$ viewing mode (training) & -2182.40 & 619.87 & $-0.53 * *$ & -1543.90 & 430.76 & $-0.37 * *$ & 0.279 & 0.257 & $0.279 * *$ \\
\hline Perceived demands (training) & & & & 66.75 & 17.17 & $0.42 * *$ & 0.429 & 0.392 & $\mathbf{0 . 1 5 0} * *$ \\
\hline Psychological flexibility & & & & -132.46 & 28.91 & $-0.48 * * *$ & 0.629 & 0.592 & $\mathbf{0 . 2 0 0} * * *$ \\
\hline Manual dexterity (bimanual) & & & & -350.59 & 130.86 & $-.29 *$ & 0.703 & 0.662 & 0.074* \\
\hline
\end{tabular}

$N=34$

$* p<0.05, * * p<0.01, * * * p<0.001$. Note. Bolded items reflect significant relationships at $p<0.05$.

Table 5 Summary of combined hierarchical stepwise regression analyses for variables predicting total test score

\begin{tabular}{|c|c|c|c|c|c|c|c|c|c|}
\hline \multirow{2}{*}{$\begin{array}{l}\text { Total test score } \\
\text { Variable }\end{array}$} & \multicolumn{3}{|c|}{ Model 1 (control) } & \multicolumn{3}{|c|}{ Model 2 (final) } & \multirow[t]{2}{*}{$R^{2}$} & \multirow[t]{2}{*}{$R_{\text {adj }}^{2}$} & \multirow[t]{2}{*}{$R^{2}$ change } \\
\hline & $B$ & SE & $\beta$ & $B$ & SE & $\beta$ & & & \\
\hline Constant & 1185.80 & 42.15 & - & 1770.44 & 198.58 & - & & & \\
\hline $2 \mathrm{D}$ vs. $3 \mathrm{D}$ viewing mode (testing) & -197.38 & 56.38 & $-0.53 * *$ & 191.37 & 50.47 & $-0.51 * *$ & 0.277 & 0.254 & $0.277 * *$ \\
\hline Manual dexterity (assembly) & & & & -13.70 & 4.57 & $-0.40 * *$ & 0.439 & 0.403 & $0.163 * *$ \\
\hline
\end{tabular}

$N=34$

${ }^{*} p<0.05, * * p<0.01, * * * p<0.001$. Note. Bolded items reflect significant relationships at $p<0.05$.

Table 6 Summary of combined hierarchical stepwise regression analyses for variables predicting total NIS score

\begin{tabular}{|c|c|c|c|c|c|c|c|c|c|}
\hline \multirow{2}{*}{$\begin{array}{l}\text { Total NIS score } \\
\text { Variable }\end{array}$} & \multicolumn{3}{|c|}{ Model 1 (Control) } & \multicolumn{3}{|c|}{ Model 2 (Final) } & \multirow[t]{2}{*}{$R^{2}$} & \multirow[t]{2}{*}{$R_{\text {adj }}^{2}$} & \multirow[t]{2}{*}{$R^{2}$ change } \\
\hline & $B$ & SE & $\beta$ & $B$ & SE & $\beta$ & & & \\
\hline Constant & 783.20 & 55.47 & - & 816.00 & 143.55 & - & & & \\
\hline $2 \mathrm{D}$ vs. $3 \mathrm{D}$ viewing mode (testing) & -410.73 & 74.20 & $-0.70 * * *$ & -400.10 & 54.74 & $-0.68 * * *$ & 0.489 & 0.473 & $0.489 * * *$ \\
\hline Visual-spatial ability & & & & -27.72 & 5.33 & $-0.48 * * *$ & 0.690 & 0.670 & $0.201 * * *$ \\
\hline Perceived demands (testing) & & & & 5.76 & 2.06 & $0.26 * *$ & 0.754 & 0.730 & $0.064 * *$ \\
\hline
\end{tabular}

$N=34$

${ }^{*} p<0.05, * * p<0.01, * * * p<0.001$. Note. Bolded items reflect significant relationships at $p<0.05$.

the task was novel and highly complex (i.e. the NIS task). Overall, these findings reiterate the limitations inherent in trying to predict surgical skill through one or two innate abilities alone. Rather, performance should be understood as the combination of physical, cognitive, visual, and psychological skills/abilities that work together to allow effective movement, attention, observation, and emotional regulation that changes with the needs of the context/task/individual. 
Table 7 Summary of regression analysis for variables predicting total follow-up score

\begin{tabular}{|c|c|c|c|c|c|c|}
\hline Total follow-up score & Model 1 & & & $R^{2}$ & $R_{\mathrm{adj}}^{2}$ & $R^{2}$ change \\
\hline Variable & $B$ & SE & $\beta$ & & & \\
\hline Constant & 1895.26 & 247.11 & - & & & \\
\hline Manual dexterity (assembly) & -23.15 & 5.70 & $-0.66 * *$ & 0.440 & 0.413 & $0.440 * *$ \\
\hline
\end{tabular}

As past research has commonly focussed on only one or two innate variables to predict surgical performance (and overlooked the combined effects of psychological factors) [20, $21]$, it is not surprising then that we find a lack of consistency in the strength and significance of various relationships throughout the field.

\section{Limitations and future research}

Despite the novelty of the current findings, the study had its limitations. First, though the sample was appropriately powered for our interpretation of the reported analyses, future studies may benefit from employing larger sample sizes to allow for greater generalisability of the results and to reduce the possibility of Type II errors. While no substantive conclusions were drawn from non-significant relationships here, several findings appear inconsistent with the outcomes of prior research. For example, unlike in previous studies [63], stereoacuity was not significantly correlated with performance, and visual acuity did not account for a significant portion of variance in performance beyond other innate variables. However, these results may have been due to a restricted range of responses (i.e. all participants were within the normal range of visual ability), and a level of shared variance with other predictors (e.g. viewing mode, manual dexterity). Consequently, future research should explore the effects of visual abilities across a broader range and a larger sample of participants.

Additionally, while the results highlight the need to expand on previous models to optimise the prediction of surgical potential, several variables were omitted from the study's design that may have accounted for further variance in participant' performance. For example, the NASA-TLX was used to measure how demanding participants perceived the tasks in this study, yet no specific measure of stress perception (i.e. perceiving the task as a threat or a challenge) was included here. Therefore, we were not able to determine whether psychological flexibility impacted performance via different stress perceptions. Furthermore, assessing other subcomponents of psychological flexibility, namely, cognitive flexibility (an aspect of executive functioning that allows flexible response adaptation and attention shifting, which has been found to correlate with psychological flexibility in other contexts) [75] may have accounted for further variance in the outcome measures and helped to explain the connections found between psychological variables and participant performance here.

In addition, as this study focussed on initial training and the early acquisition of skills, we cannot determine whether the value of psychological flexibility is limited to overcoming the initial challenges and frustrations involved in early training, or whether there are broader implications for practice. For example, if such results are found in a controlled training environment, it begs the question: What kind of impact could psychological flexibility have on the performance of early career surgeons who continuously face challenges, uncertainty, and extreme demands while practicing in the high-stakes operational context? Consequently, further exploration is required into how the potential for extreme stress (i.e. high perceived task demands, threat perceptions, and/or low psychological flexibility) in early training impacts performance in the later stages of training and performance in the real operational context. Thankfully, unlike innate abilities that can be particularly difficult to change/ improve over time, research shows that psychological flexibility is a skill that may be taught and/or increased through mindfulness-based practice [76-79]. Furthermore, as mindfulness-based practice has already been linked to improved well-being and performance in laparoscopic skills training [60], the combined assessment of psychological flexibility and mindfulness may help to broaden our understanding of performance and establish more effective and individualised tools to prepare potential candidates for a surgical career.

\section{Conclusion}

Overall, the current results highlight the importance of assessing physical, cognitive, visual, and psychological functioning to predict surgical potential. Moreover, this research provides a novel insight into the value of psychological functioning to increase the efficiency of proficiencybased laparoscopic skills training. With further exploration into these and other variables of interest (e.g. cognitive flexibility, attention, mindfulness, stress perceptions), we may be able to develop more reliable tools/guides to enhance the self-selection and self-development of surgical candidates. In doing so, these candidates may be more likely to possess 
the necessary aptitude and attitude to reach laparoscopic proficiency with increased efficiency and efficacy, with benefits for surgeons, patients, and the healthcare system alike.

\section{Declarations}

Disclosures Kirsty L. Beattie, Andrew Hill, Mark S. Horswill, Philip M. Grove, and Andrew R. L. Stevenson have no conflicts of interest or financial ties to disclose.

Open Access This article is licensed under a Creative Commons Attribution 4.0 International License, which permits use, sharing, adaptation, distribution and reproduction in any medium or format, as long as you give appropriate credit to the original author(s) and the source, provide a link to the Creative Commons licence, and indicate if changes were made. The images or other third party material in this article are included in the article's Creative Commons licence, unless indicated otherwise in a credit line to the material. If material is not included in the article's Creative Commons licence and your intended use is not permitted by statutory regulation or exceeds the permitted use, you will need to obtain permission directly from the copyright holder. To view a copy of this licence, visit http://creativecommons.org/licenses/by/4.0/.

\section{References}

1. Mitchell EL, Arora S (2012) How educational theory can inform the training and practice of vascular surgeons. J Vasc Surg 56:530-537. https://doi.org/10.1016/j.jvs.2012.01.065

2. Reznick RK, MacRae H (2006) Teaching surgical skills—changes in the wind. N Engl J Med 355:2664-2669. https://doi.org/10. 1056/NEJMra054785

3. Grantcharov TP, Funch-Jensen P (2009) Can everyone achieve proficiency with the laparoscopic technique? Learning curve patterns in technical skills acquisition. Am J Surg 197:447-449. https://doi.org/10.1016/j.amjsurg.2008.01.024

4. Louridas M, Szasz P, Fecso AB, Zywiel MG, Lak P, Bener AB, Harris KA, Grantcharov TP (2017) Practice does not always make perfect: need for selection curricula in modern surgical training. Surg Endosc 31:3718-3727. https://doi.org/10.1007/ s00464-017-5572-3

5. Schijven MP, Jakimowicz J (2004) The learning curve on the Xitact LS 500 laparoscopy simulator: profiles of performance. Surg Endosc 18:121-127. https://doi.org/10.1007/ s00464-003-9040-x

6. Ansell JS, Boughton R, Cullen T, Hodges C, Nation E, Peters P, Scardino P (1979) Lack of agreement between subjective ratings of instructors and objective testing of knowledge acquisition in a urological continuing medical education course. J Urol 122:721723. https://doi.org/10.1016/S0022-5347(17)56572-6

7. Cuschieri A, Francis N, Crosby J, Hanna GB (2001) What do master surgeons think of surgical competence and revalidation? Am J Surg 182:110-116. https://doi.org/10.1016/S0002-9610(01) 00667-5

8. Schaverien M (2016) Selection for surgical training: an evidencebased review. J Surg Educ 73:721-729. https://doi.org/10.1016/j. jsurg.2016.02.007

9. Gallagher AG, Leonard G, Traynor OJ (2009) Role and feasibility of psychomotor and dexterity testing in selection for surgical training. ANZ J Surg 79:108-113. https://doi.org/10.1111/j.14452197.2008.04824.x
10. Buckley CE, Kavanagh DO, Nugent E, Ryan D, Traynor OJ, Neary PC (2014) The impact of aptitude on the learning curve for laparoscopic suturing. Am J Surg 207:263-270. https://doi.org/10. 1016/j.amjsurg.2013.08.037

11. Harrington CM, Dicker P, Traynor O, Kavanagh DO (2018) Visuospatial abilities and fine motor experiences influence acquisition and maintenance of fundamentals of laparoscopic surgery (FLS) task performance. Surg Endosc 32:4639-4648. https://doi.org/10. 1007/s00464-018-6220-2

12. Kramp KH, van Det MJ, Hoff C, Veeger NJGM, ten Cate Hoedemaker HO, Pierie J-PEN (2016) The predictive value of aptitude assessment in laparoscopic surgery: a meta-analysis. Med Educ 50:409-427. https://doi.org/10.1111/medu.12945

13. Maan ZN, Maan IN, Darzi AW, Aggarwal R (2012) Systematic review of predictors of surgical performance. Br J Surg 99:1610 1621. https://doi.org/10.1002/bjs.8893

14. Stefanidis D, Korndorffer JR Jr, Black FW, Dunne JB, Sierra R, Touchard CL, Rice DA, Markert RJ, Kastl PR, Scott DJ (2006) Psychomotor testing predicts rate of skill acquisition for proficiency-based laparoscopic skills training. Surgery 140:252-262. https://doi.org/10.1016/j.surg.2006.04.002

15. Vajsbaher T, Schultheis H, Francis NK (2018) Spatial cognition in minimally invasive surgery: a systematic review. BMC Surg 18:94-94. https://doi.org/10.1186/s12893-018-0416-1

16. Groenier M, Groenier KH, Miedema HAT, Broeders IAMJ (2015) Perceptual speed and psychomotor ability predict laparoscopic skill acquisition on a simulator. J Surg Educ 72:1224-1232. https://doi.org/10.1016/j.jsurg.2015.07.006

17. Masud D, Undre S, Darzi A (2012) Using manual dexterity to predict the quality of the final product in the small bowel anastomosis after a period of training. Am J Surg 203:776-781. https:// doi.org/10.1016/j.amjsurg.2011.06.054

18. Sakata S, Grove PM, Hill A, Watson MO, Stevenson ARL (2017) Impact of simulated three-dimensional perception on precision of depth judgements, technical performance and perceived workload in laparoscopy. Br J Surg 104:1097-1106. https://doi.org/10.1002/ bjs. 10528

19. Sakata S, Watson MO, Grove PM, Stevenson ARL (2016) The conflicting evidence of three-dimensional displays in laparoscopy: a review of systems old and new. Ann Surg 263:234-239. https:// doi.org/10.1097/SLA.0000000000001504

20. Hedman L, Ström P, Andersson P, Kjellin A, Wredmark T, Felländer-Tsai L (2006) High-level visual-spatial ability for novices correlates with performance in a visual-spatial complex surgical simulator task. Surg Endosc 20:1275-1280. https://doi.org/10. 1007/s00464-005-0036-6

21. Gallagher AG, Cowie R, Crothers I, Jordan-Black JA, Satava RM (2003) PicSOr: an objective test of perceptual skill that predicts laparoscopic technical skill in three initial studies of laparoscopic performance. Surg Endosc 17:1468-1471. https://doi.org/10.1007/ s00464-002-8569-4

22. Louridas M, Szasz P, de Montbrun S, Harris KA, Grantcharov TP (2016) Can we predict technical aptitude? A systematic review. Ann Surg 263:673-691. https://doi.org/10.1097/SLA.0000000000 001283

23. Ritter EM, McClusky DA, Gallagher AG, Enochsson L, Smith CD (2006) Perceptual, visuospatial, and psychomotor abilities correlate with duration of training required on a virtual-reality flexible endoscopy simulator. Am J Surg 192:379-384. https://doi.org/10. 1016/j.amjsurg.2006.03.003

24. Arora S, Sevdalis N, Aggarwal R, Sirimanna P, Darzi A, Kneebone R (2010) Stress impairs psychomotor performance in novice laparoscopic surgeons. Surg Endosc 24:2588-2593. https://doi. org/10.1007/s00464-010-1013-2

25. Moorthy K, Munz Y, Dosis A, Bann S, Darzi A (2003) The effect of stress-inducing conditions on the performance of a laparoscopic 
task. Surg Endosc 17:1481-1484. https://doi.org/10.1007/ s00464-002-9224-9

26. Wetzel CM, Black SA, Hanna GB, Athanasiou T, Kneebone RL, Nestel D, Wolfe JHN, Woloshynowych M (2010) The effects of stress and coping on surgical performance during simulations. Ann Surg 251:171-176. https://doi.org/10.1097/SLA.0b013e3181 b3b2be

27. Hou G, Zhang Y, Zhao N, Chen R, Xiao W, Yu H, Wang J, Yuan T-F (2015) Mental abilities and performance efficacy under a simulated 480-m helium-oxygen saturation diving. Front Psychol 6:979-979. https://doi.org/10.3389/fpsyg.2015.00979

28. Vine SJ, Freeman P, Moore LJ, Chandra-Ramanan R, Wilson MR (2013) Evaluating stress as a challenge is associated with superior attentional control and motor skill performance: testing the predictions of the biopsychosocial model of challenge and threat. J Exp Psychol Appl 19:185-194. https://doi.org/10.1037/a0034106

29. Wu J, Yan J (2017) Editorial: stress and cognition. Front Psychol 8:970-970. https://doi.org/10.3389/fpsyg.2017.00970

30. Anton NE, Mizota T, Timsina LR, Whiteside JA, Myers EM, Stefanidis D (2019) Attentional selectivity, automaticity, and selfefficacy predict simulator-acquired skill transfer to the clinical environment. Am J Surg 217:266-271. https://doi.org/10.1016/j. amjsurg.2018.11.028

31. Anton NE, Beane J, Yurco AM, Howley LD, Bean E, Myers EM, Stefanidis D (2018) Mental skills training effectively minimizes operative performance deterioration under stressful conditions: results of a randomized controlled study. Am J Surg 215:214-221. https://doi.org/10.1016/j.amjsurg.2017.09.039

32. Hassan I, Weyers P, Maschuw K, Dick B, Gerdes B, Rothmund M, Zielke A (2006) Negative stress-coping strategies among novices in surgery correlate with poor virtual laparoscopic performance. Br J Surg 93:1554-1559. https://doi.org/10.1002/bjs.5544

33. Malhotra N, Poolton JM, Wilson MR, Fan JK, Masters RS (2014) Conscious motor processing and movement self-consciousness: two dimensions of personality that influence laparoscopic training. J Surg Educ 71:798-804. https://doi.org/10.1016/j.jsurg.2014.04. 003

34. Malhotra N, Poolton JM, Wilson MR, Leung G, Zhu F, Fan JK, Masters RS (2015) Exploring personality dimensions that influence practice and performance of a simulated laparoscopic task in the objective structured clinical examination. J Surg Educ 72:662-669. https://doi.org/10.1016/j.jsurg.2014.12.011

35. Ng R, Chahine S, Lanting B, Howard J (2019) Unpacking the literature on stress and resiliency: a narrative review focused on learners in the operating room. J Surg Educ 76:343-353. https:// doi.org/10.1016/j.jsurg.2018.07.025

36. Rosenthal R, Schäfer J, Hoffmann H, Vitz M, Oertli D, Hahnloser D (2013) Personality traits and virtual reality performance. Surg Endosc 27:222-230. https://doi.org/10.1007/s00464-012-2424-Z

37. Stefanidis D, Anton NE, Howley LD, Bean E, Yurco A, Pimentel ME, Davis CK (2016) Effectiveness of a comprehensive mental skills curriculum in enhancing surgical performance: results of a randomized controlled trial. Am J Surg 213:318-324. https://doi. org/10.1016/j.amjsurg.2016.10.016

38. Stienen MN, Scholtes F, Samuel R, Weil A, Weyerbrock A, Surbeck W (2018) Different but similar: personality traits of surgeons and internists-results of a cross-sectional observational study. BMJ Open 8:e021310-e021310. https://doi.org/10.1136/bmjop en-2017-021310

39. Bann S, Darzi A (2005) Selection of individuals for training in surgery. Am J Surg 190:98-102. https://doi.org/10.1016/j.amjsu rg.2005.04.002

40. Yule S, Flin R, Paterson-Brown S, Maran N (2006) Non-technical skills for surgeons in the operating room: a review of the literature. Surgery 139:140-149. https://doi.org/10.1016/j.surg.2005.06.017
41. Birkmeyer JD, Birkmeyer NJO, Finks JF, O'Reilly A, Oerline M, Carlin AM, Nunn AR, Dimick J, Banerjee M (2013) Surgical skill and complication rates after bariatric surgery. N Engl J Med 369:1434-1442. https://doi.org/10.1056/NEJMsa1300625

42. Vine SJ, Moore LJ, Wilson MR (2016) An integrative framework of stress, attention, and visuomotor performance. Front Psychol 7:1671-1671. https://doi.org/10.3389/fpsyg.2016.01671

43. Bijlsma T, Muis S, van Tilborg A (2018) Developments and advances in defense and security. Springer, Cham, pp 183-192

44. Bryan CJ, Ray-Sannerud B, Heron EA (2015) Psychological flexibility as a dimension of resilience for posttraumatic stress, depression, and risk for suicidal ideation among Air Force personnel. J Contextual Behav Sci 4:263-268. https://doi.org/10.1016/j. jcbs.2015.10.002

45. Gardner FL, Moore ZE (2004) A mindfulness-acceptance-commitment-based approach to athletic performance enhancement: Theoretical considerations. Behav Ther 35:707-723. https://doi. org/10.1016/s0005-7894(04)80016-9

46. Gautam A, Mathur R (2018) Influence of mindfulness on decision making and psychological flexibility among aircrew. J Psychosoc Res 13:199-207. https://doi.org/10.32381/JPR.2018.13.01.19

47. Johles L, Gustafsson H, Jansson-Fröjmark M, Classon C, Hasselqvist J, Lundgren T (2020) Psychological flexibility among competitive athletes: a psychometric investigation of a new scale. Front Sports Act Living 2:110-110. https://doi.org/10.3389/fspor. 2020.00110

48. Lundgren T, Reinebo G, Naslund M, Parling T (2020) Acceptance and commitment training to promote psychological flexibility in ice hockey performance: a Controlled Group Feasibility Study. J Clin Sport Psychol 14:170-181. https://doi.org/10.1123/jcsp. 2018-0081

49. Hayes SC, Villatte M, Levin M, Hildebrandt M (2011) Open, aware, and active: contextual approaches as an emerging trend in the behavioral and cognitive therapies. Annu Rev Clin Psychol 7:141-168. https://doi.org/10.1146/annurev-clinp sy-032210-104449

50. Hoffmann D, Rask CU, Frostholm L (2019) Chapter Seven Acceptance and commitment therapy for health anxiety. In: Hedman-Lagerlöf E (ed) The clinician's guide to treating health anxiety. Academic Press, London, pp 123-142

51. Alkoby A, Pliskin R, Halperin E, Levit-Binnun N (2019) An eight-week mindfulness-based stress reduction (MBSR) workshop increases regulatory choice flexibility. Emotion 19:593-604. https://doi.org/10.1037/emo0000461

52. Sagui-Henson SJ, Levens SM, Blevins CL (2018) Examining the psychological and emotional mechanisms of mindfulness that reduce stress to enhance healthy behaviours. Stress Health 34:379-390. https://doi.org/10.1002/smi.2797

53. Stanley EA (2014) Mindfulness-based mind fitness training: an approach for enhancing performance and building resilience in high-stress contexts. In: Ie A, Ngnoumen CT, Langer EJ (eds) The Wiley blackwell handbook of mindfulness. Wiley-Blackwell, London, pp 964-985

54. Bond FW, Flaxman PE, Lloyd J (2016) Mindfulness and meditation in the workplace: an acceptance and commitment therapy approach. The psychology of meditation: research and practice. Oxford University Press, New York, pp 241-258

55. de Leval MR, Carthey J, Wright DJ, Farewell VT, Reason JT (2000) Human factors and cardiac surgery: a multicenter study. J Thorac Cardiovasc Surg 119:661-672. https://doi.org/10.1016/ S0022-5223(00)70006-7

56. Catchpole KR, Giddings AEB, Wilkinson M, Hirst G, Dale T, de Leval MR (2007) Improving patient safety by identifying latent failures in successful operations. Surgery 142:102-110. https:// doi.org/10.1016/j.surg.2007.01.033 
57. McCracken LM, Yang S-Y (2008) A contextual cognitive-behavioral analysis of rehabilitation workers' health and well-being: influences of acceptance, mindfulness, and values-based action. Rehabil Psychol 53:479-485. https://doi.org/10.1037/a0012854

58. Pakenham KI (2015) Effects of acceptance and commitment therapy (ACT) training on clinical psychology trainee stress, therapist skills and attributes, and ACT processes. Clin Psychol Psychother 22:647-655. https://doi.org/10.1002/cpp.1924

59. Ramaci T, Bellini D, Presti G, Santisi G (2019) Psychological flexibility and mindfulness as predictors of individual outcomes in hospital health workers. Front Psychol 10:1302-1302. https:// doi.org/10.3389/fpsyg.2019.01302

60. Lebares CC, Guvva EV, Olaru M, Sugrue LP, Staffaroni AM, Delucchi KL, Kramer JH, Ascher NL, Harris HW (2019) Efficacy of mindfulness-based cognitive training in surgery: additional analysis of the mindful surgeon pilot randomized clinical trial. JAMA Netw Open 2:e194108. https://doi.org/10.1001/jamanetwor kopen.2019.4108

61. Beattie KL, Hill A, Horswill MS, Grove PM, Stevenson ARL (2020) Laparoscopic skills training: the effects of viewing mode (2D vs 3D) on skill acquisition and transfer. Surg Endosc. https:// doi.org/10.1007/s00464-020-07923-8

62. Schreuder H, van den Berg C, Hazebroek E, Verheijen R, Schijven M (2011) Laparoscopic skills training using inexpensive box trainers: which exercises to choose when constructing a validated training course. BJOG 118:1576-1584. https://doi.org/10.1111/j. 1471-0528.2011.03146.x

63. Sakata S, Grove PM, Watson MO, Stevenson ARL (2017) The impact of crosstalk on three-dimensional laparoscopic performance and workload. Surg Endosc 31:4044-4050. https://doi. org/10.1007/s00464-017-5449-5

64. Peters M, Laeng B, Latham K, Jackson M, Zaiyouna R, Richardson $C$ (1995) A redrawn Vandenberg and Kuse mental rotations test - different versions and factors that affect performance. Brain Cogn 28:39-58. https://doi.org/10.1006/brcg.1995.1032

65. Yurko YY, Scerbo MW, Prabhu AS, Acker CE, Stefanidis D (2010) Higher mental workload is associated with poorer laparoscopic performance as measured by the NASA-TLX tool. Simul Healthc 5:267-271. https://doi.org/10.1097/SIH.0b013e3181 e3f329

66. Hart SG, Staveland LE (1988) Development of NASA-TLX (Task Load Index): Results of Empirical and Theoretical Research. Human Mental Workload, North-Holland pp 139-183

67. Santomauro CM, Hill A, McCurdie T, McGlashan HL (2020) Improving the quality of evaluation data in simulation-based healthcare improvement projects: a practitioner's guide to choosing and using published measurement tools. Simul Healthc 15:341-355. https://doi.org/10.1097/SIH.0000000000000442

68. Ruan S, Wobbrock J, Liou K, Ng A, Landay J (2018) Comparing speech and keyboard text entry for short messages in two languages on touchscreen phones. Proc ACM Interact Mob Wearable Ubiquitous Technol 1:1-23. https://doi.org/10.1145/3161187

69. Bond F, Hayes S, Baer R, Carpenter K, Guenole N, Orcutt H, Waltz T, Zettle R (2011) Preliminary psychometric properties of the Acceptance and Action Questionnaire- II: a revised measure of psychological flexibility and acceptance. Behav Ther 42:676-688. https://doi.org/10.1016/j.beth.2011.03.007

70. Field AP (2009) Discovering statistics using SPSS, 3rd edn. SAGE, London

71. Poudel S, Kurashima Y, Watanabe Y, Ebihara Y, Tamoto E, Murakami S, Nakamura T, Tsuchikawa T, Okamura K, Shichinohe T, Hirano S (2017) Impact of 3D in the training of basic laparoscopic skills and its transferability to $2 \mathrm{D}$ environment: a prospective randomized controlled trial. Surg Endosc 31:11111118. https://doi.org/10.1007/s00464-016-5074-8

72. Sorensen SM, Savran MM, Konge L, Bjerrum F (2016) Threedimensional versus two-dimensional vision in laparoscopy: a systematic review. Surg Endosc 30:11-23. https://doi.org/10.1007/ s00464-015-4189-7

73. Austin PC, Steyerberg EW (2015) The number of subjects per variable required in linear regression analyses. J Clin Epidemiol 68:627-636. https://doi.org/10.1016/j.jclinepi.2014.12.014

74. Jenkins DG, Quintana-Ascencio PF (2020) A solution to minimum sample size for regressions. PLoS ONE 15:e0229345-e0229345. https://doi.org/10.1371/journal.pone.0229345

75. Whiting DL, Deane FP, Simpson GK, McLeod HJ, Ciarrochi J (2017) Cognitive and psychological flexibility after a traumatic brain injury and the implications for treatment in acceptancebased therapies: a conceptual review. Neuropsychol Rehabil 27:263-299. https://doi.org/10.1080/09602011.2015.1062115

76. Bond FW, Flaxman PE, van Veldhoven MJPM, Biron M (2010) The impact of psychological flexibility and Acceptance and Commitment Therapy (ACT) on Health and Productivity at Work. In: Houdmont J, Leka S (eds) Contemporary occupational health psychology. Wiley, Chichester, pp 296-313

77. Bond FW, Lloyd J, Guenole N (2013) The work-related acceptance and action questionnaire: initial psychometric findings and their implications for measuring psychological flexibility in specific contexts. J Occup Organ Psychol 86:331-347. https://doi.org/ 10.1111/joop. 12001

78. Dehghani M, Saf AD, Vosoughi A, Tebbenouri G, Zarnagh HG (2018) Effectiveness of the mindfulness-acceptance-commitmentbased approach on athletic performance and sports competition anxiety: a randomized clinical trial. Electron Physician 10:67496755. https://doi.org/10.19082/6749

79. Shapiro SL, Astin JA, Bishop SR, Cordova M (2005) Mindfulness-based stress reduction for health care professionals: results from a randomized trial. Int J Stress Manag 12:164-176. https:// doi.org/10.1037/1072-5245.12.2.164

Publisher's Note Springer Nature remains neutral with regard to jurisdictional claims in published maps and institutional affiliations. 